\title{
Comparative transcriptome analysis between planarian Dugesia japonica and other platyhelminth species
}

\author{
Osamu Nishimura ${ }^{1,2}$, Yukako Hirao ${ }^{2,3}$, Hiroshi Tarui ${ }^{2,4}$ and Kiyokazu Agata ${ }^{1 *}$
}

\begin{abstract}
Background: Planarians are considered to be among the extant animals close to one of the earliest groups of organisms that acquired a central nervous system (CNS) during evolution. Planarians have a bilobed brain with nine lateral branches from which a variety of external signals are projected into different portions of the main lobes. Various interneurons process different signals to regulate behavior and learning/memory. Furthermore, planarians have robust regenerative ability and are attracting attention as a new model organism for the study of regeneration. Here we conducted large-scale EST analysis of the head region of the planarian Dugesia japonica to construct a database of the head-region transcriptome, and then performed comparative analyses among related species.

Results: A total of 54,752 high-quality EST reads were obtained from a head library of the planarian Dugesia japonica, and 13,167 unigene sequences were produced by de novo assembly. A new method devised here revealed that proteins related to metabolism and defense mechanisms have high flexibility of amino-acid substitutions within the planarian family. Eight-two CNS-development genes were found in the planarian (cf. C. elegans 3; chicken 129). Comparative analysis revealed that $91 \%$ of the planarian CNS-development genes could be mapped onto the schistosome genome, but one-third of these shared genes were not expressed in the schistosome.

Conclusions: We constructed a database that is a useful resource for comparative planarian transcriptome studies. Analysis comparing homologous genes between two planarian species showed that the potential of genes is important for accumulation of amino-acid substitutions. The presence of many CNS-development genes in our database supports the notion that the planarian has a fundamental brain with regard to evolution and development at not only the morphological/functional, but also the genomic, level. In addition, our results indicate that the planarian CNS-development genes already existed before the divergence of planarians and schistosomes from their common ancestor.
\end{abstract}

\section{Background}

The flatworm planarian Dugesia japonica inhabits fresh water in East Asian areas and is the most common planarian in Japan [1]. Planarians are members of the phylum Platyhelminthes, a group of organisms that are thought to have acquired a central nervous system (CNS) with a simple brain structure early during evolution [2-4]. The constitution of the planarian CNS and

\footnotetext{
*Correspondence: agata@mdb.biophys.kyoto-u.ac.jp

'Department of Biophysics and Global COE Program, Graduate School of Science, Kyoto University, Kitashirakawa-Oiwake, Sakyo-ku, Kyoto, Japan Full list of author information is available at the end of the article
}

neural network has been visualized in detail by whole mount in situ hybridization and immunofluorescence studies, and fluorescent dye tracing experiments [5-8]: the CNS is composed of a brain (anterior cephalic ganglion) in the head region and a pair of ventral nerve cords extending anterior to posterior along the ventral side of the body, with the brain and ventral nerve cords being morphologically distinguishable structures. Neurons from a variety of sensory organs, such as eyes and auricles, project to different portions of the main lobes $[6,8,9]$. These interneurons are involved in information processing of external signals and work to regulate

\section{Biomed Central}


behavior and learning/memory [10-12]. The planarian brain acts as an information center of the nervous system, and shows fundamental evolutionarily conserved features of the animal brain not only morphologically but also functionally [12]. In addition, planarians are attracting attention as new model organism for regeneration, including brain regeneration, research. Interestingly, planarians can regenerate their well-organized brains from any portion of their bodies utilizing adult somatic pluripotent stem cells (neoblasts) [13-15]. The RNA interference technique can be applied in planarians to identify gene functions [16], and single-cell level gene profiling is also possible based on a combination of fluorescence activated cell sorting (FACS) and quantitative reverse transcription polymerase chain reaction (qRT-PCR) [17,18].

In recent years, resources for comparative transcriptome analysis among members of the phylum Platyhelminthes have accumulated rapidly. The planarian Schmidtea mediterranea and blood-fluke Schistosoma mansoni genome sequences have been analyzed [19,20], and transcriptome resources and analyses have been reported [21-23]. Unigene Build \#4 for planarian S. mediterranea, which is based on the Sanger sequencing method, contains 10,173 clusters from 69,699 EST sequences, which were obtained from juvenile and adult libraries $[24,25]$. Some studies with massive numbers of sequencing reads produced from next generation sequencing technologies, include the Illumina HiSeq, Roche 454 and Life Technologies SOLiD, have been reported [26-28]. However, there is no genomic resource for $D$. japonica, and only limited transcriptome information is available for this species. Despite the large evolutionary distance between these two planarians [29], they share not just morphological similarity, but also genes, CNS features and regeneration ability [30].

The cDNA libraries of the schistosome $S$. mansoni cover its various life stages: egg, miracidium, sporocyst, cercaria, larva and adult, with a total of 152,704 sequences and 10,061 clusters (Unigene Build \#19) [24]. Schistosomes are triploblastic animals and members of Platyhelminthes, like planarians, with which they share not only body shape but also basic organismal functions. Specifically, they have bilateral symmetry, a functional brain and peripheral nerves, ventral suckers, digestive and excretory organs; and lack a cardiovascular system [31]. Moreover, many genes and their amino acid sequences are well conserved between schistosomes and planarians. However, whereas planarians are free-living flatworms that prey on other organisms, schistosomes, which are major agents of the disease schistosomiasis and parasitize multiple hosts and organs, change their morphology to adapt to their living environments [32]. The life cycles of these two genuses are thus in sharp contrast, requiring brain functions and metabolic processes that are quite different.

To establish a database of genetic information for planarian transcriptome studies, we performed a largescale EST project for the planarian D. japonica using head cDNA libraries. We adopted Sanger sequencing in order to decrease the sequence gaps, frame-shift errors, and the misassembly that can occur due to splice variants and to the short reads produced by next generation sequencing. These factors are important for the identification of long consensus sequences between conserved proteins. We compared the percentage of amino acid substitutions between $D$. japonica and its sister species $S$. mediterranea using the homologue proteins to identify genes whose mutability enables accommodation to different environmental conditions. For this analysis, we developed a method to extract gene groups that have different rates of evolution in close species that have very-well-conserved proteins.

We have already published a partial analysis of $D$. japonica transcriptome [33], and have identified several genes that are specifically expressed in the CNS $[7,9,34]$. However, those studies were insufficient for the exhaustive comparative analyses between planarians and members of the same family or the same phylum necessary for clarifying the composition and evolution of the CNS. As compared with model organisms, the gene information of Platyhelminthes is very limited. For these reasons we used Gene Ontology [35], which is based on information across many species, including vertebrates and non-vertebrates, and serves as a common platform to compare and annotate non-model organisms.

In this study, we focused on the CNS-development genes, which should give information about the evolutionary position of Platyhelminthes. To examine the genomic evolution and the presence of gene expression, we compared the $D$. japonica unigenes with not only $S$. mansoni unigenes but also the predicted protein information from the genome sequence. The traces we thereby found on the genome suggested the possibility that these genes were derived from the common ancestor of these two genuses, and the divergent gene expression between these genuses provided information about their adaptation to their specific habitats.

\section{Results}

\section{EST sequencing}

A non-normalized cDNA library was constructed using poly $(\mathrm{A})+$ RNA isolated from the heads of adult planarians. Two different experimental methods and DNA sequencers were used for the cDNA template amplification and DNA sequencing reaction (Table 1). After trimming of vector sequences, about $84.7 \%$ of reads passed the high-quality control for Phred base calling [36], and 
Table 1 Summary of the materials used in the EST analysis

\begin{tabular}{|c|c|c|c|c|c|c|c|c|c|}
\hline Library & Prefix & $\begin{array}{l}\text { Plate } \\
\text { number }\end{array}$ & $\begin{array}{l}\text { CDNA } \\
\text { amplification }\end{array}$ & $\begin{array}{l}\text { Sequence } \\
\text { primer }\end{array}$ & $\begin{array}{l}\text { DNA } \\
\text { sequencer }\end{array}$ & $\begin{array}{l}\text { Valid 5' } \\
\text { reads }\end{array}$ & $\begin{array}{l}\text { Valid 3' } \\
\text { reads }\end{array}$ & $\begin{array}{l}\text { Overlap } \\
\text { contigs }\end{array}$ & $\begin{array}{l}\text { Full insert } \\
\text { sequences }\end{array}$ \\
\hline Eye & Dj_aE & 000 & Plasmid & SK & ABI 3700 & $918^{*}$ & - & - & - \\
\hline Head & Dj_aH & 000 & Plasmid & SK, M13 & $A B \mid 3700$ & $6,444^{*}$ & 3,163 & 689 & 495 \\
\hline Head & Dj_aH & $001-022$ & Plasmid & SK & $\mathrm{ABI} 3700$ & 5,024 & - & - & 21 \\
\hline Head & Dj_aH & $101-140$ & Plasmid & SK & $A B \mid 3700$ & 2,364 & - & - & 4 \\
\hline Head & Dj_aH & $201-227$ & TempliPhi & SK & $\mathrm{ABI} 3730 \mathrm{xl}$ & 8,426 & - & - & 52 \\
\hline Head & Dj_aH & $301-327$ & TempliPhi & SK, M13 & ABI 3730xI & 8,366 & 7,107 & 4,516 & 21 \\
\hline Head & Dj_aH & $401-406$ & TempliPhi & T3 & $\mathrm{ABI} 3730 \mathrm{xl}$ & 2,056 & - & - & - \\
\hline Head & Dj_aH & $501-530$ & TempliPhi & T3, M13 & $\mathrm{ABI} 3730 \mathrm{xl}$ & 9,462 & 8,191 & 5,888 & - \\
\hline Total & & & & & & 43,060 & 18,461 & 11,093 & 593 \\
\hline
\end{tabular}

* DDBJ entries registered by previous research.

finally a total of 35,698 5'-end and 18,461 3'-end reads enabled the assembly analysis to proceed accurately. For 593 clones, the reading gap was closed to get the whole clone sequence by the primer walking method using custom primers based on the EST sequence. All EST reads and full-length clone sequences have been submitted to DDBJ. The accession numbers are 5' ESTs [DDBJ: FY925127 - FY960824], 3' ESTs [DDBJ: FY960825 FY979285] and full-insert sequences [DDBJ: AK388576 AK389168].

\section{De novo transcriptome assembly}

Before de novo assembly, to generate accurate unigenes, 11,093 paired-assembly contigs were produced (Table 1) using paired-end sequences of the same clone and CAP3 assembler software [37]. After the addition of 7,362 DDBJ entries registered from previous research (Additional file 1), the complete sequence materials without the original reads that were members of paired-assembly contigs were further assembled into 4,883 contigs using TGICL software [38]. In addition, 8,284 sequences remained as singletons, resulting in a total of 13,167 unique sequences (Table 2). The average length of contigs was $1,360 \mathrm{bp}$, and the sum of all unique sequences was $12.6 \mathrm{Mbp}$, including singletons (Table 2). Figure 1 shows the distribution of the number of contigs with a particular length among the unigenes. The longest contig length was $6,040 \mathrm{bp}$. The histogram of contig depth showed that contigs with fewer than 4 copies and singletons accounted for $87 \%$ of unique sequences. In contrast, only 2 highly expressed contigs dominated the whole transcriptome sequences (Table 3). These profiles were consistent with the results of general nonnormalized transcriptome analysis [39,40]. To estimate the transcriptome coverage for the data set, we assembled 2,000 replicate random sequences and calculated the non-redundant gene numbers (Figure 2). The workflow for the assembly construction process is shown in Figure 3.

\section{Unigene annotations}

The annotations of the $D$. japonica transcriptome were based on three types of approach: homology searching by BLAST [41], conserved protein domain detection [42], and Gene Ontology [35] classification. The BLASTX search against the NCBI Protein Reference Sequences database (RefSeq) [43,44] resulted in 7,334 (55.7\%) unigene hits with significant similarity. The taxonomic distribution per organism using the best hit showed high similarity $(2,184,16.6 \%)$ with the schistosome, which belongs to the same phylum as planarians (Figure 4). Many planarian genes showed similarity to genes in not only the schistosome but also other organisms, including the hemichordate S. kowalevskii (520), chordate B. floridae (429), echinoderm S. purpuratus (242), and vertebrate $D$. rerio (221).

The conserved domain information for the transcriptome was obtained through the Pfam database [45] using RPS-BLAST, which scans a set of pre-calculated position-specific scoring matrices with a protein query. A

Table 2 Statistics of the de novo transcriptome assembly

\begin{tabular}{lcccc}
\hline & Number & Total base (bp) & Average length (bp) & Median (bp) \\
\hline Contigs & 4,883 & $6,642,939$ & 1360.4 & 7,252 \\
\hline Singletons & 8,284 & $5,919,589$ & 701.1 & 672 \\
\hline Unique sequences & 13,167 & $12,562,528$ & 940.5 & 846 \\
\hline
\end{tabular}

Summary of the de novo transcriptome assembly using filter-passed and vector trimmed reads, pre-assembly contigs, and full-insert sequences. 


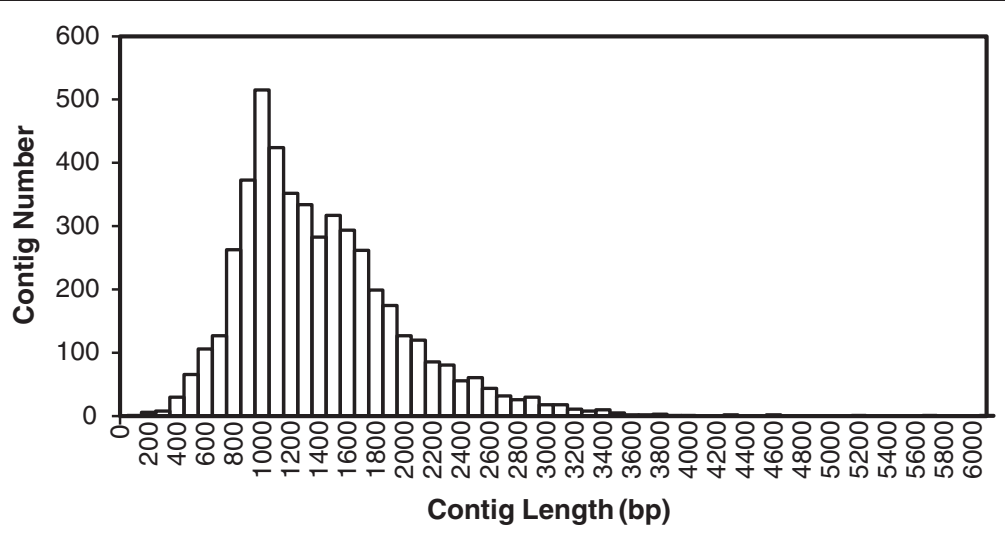

Figure 1 Distribution of number of sequences per contig in the unigenes.

total 4,609 (35.0\%) conserved protein domains with 1,558 variations were confirmed in the complete set of unigenes. Protein kinase domains were the most frequent, with 307 hits, and the second- and third- most frequent domains were ankyrin repeats (101 hits) and RNA recognition motifs (71 hits) (Table 4). Domains with less than 5 hits consist mostly of the result (2,594 hits).

To address the functional categories of the D. japonica transcriptome, all the unigenes were assigned a Gene Ontology (GO) classification based on BLASTX hits against the UniProtKB/Swiss-Prot database [46], which has reliable information for GO terms, and the annotation based on related studies. By referring to each $\mathrm{GO}$ term from the UniProt database, the terms associated with the unigenes were consolidated into higher classes using GO slim digestion [47] via software [48].

Table 3 Histogram of cluster sizes for $D$. japonica unigenes

\begin{tabular}{llcc}
\hline $\begin{array}{l}\text { Contig } \\
\text { depth }\end{array}$ & $\begin{array}{l}\text { Number of } \\
\text { contigs }\end{array}$ & $\begin{array}{l}\text { Percentage of } \\
\text { unigenes }\end{array}$ & Integration \\
\hline 1 & 8,488 & $63.81 \%$ & $63.48 \%$ \\
\hline 2 & 1,686 & $12.67 \%$ & $76.09 \%$ \\
\hline $3-4$ & 1,423 & $10.70 \%$ & $86.73 \%$ \\
\hline $5-8$ & 922 & $6.93 \%$ & $93.63 \%$ \\
\hline $9-16$ & 471 & $3.54 \%$ & $97.15 \%$ \\
\hline $17-32$ & 217 & $1.63 \%$ & $98.77 \%$ \\
\hline $33-64$ & 96 & $0.72 \%$ & $99.49 \%$ \\
\hline $65-128$ & 46 & $0.35 \%$ & $99.84 \%$ \\
\hline $129-256$ & 17 & $0.13 \%$ & $99.96 \%$ \\
\hline $257-512$ & 3 & $0.02 \%$ & $99.99 \%$ \\
\hline $513-1,024$ & 0 & $0.00 \%$ & $99.99 \%$ \\
\hline $1,025-2,048$ & 1 & $0.01 \%$ & $99.99 \%$ \\
\hline $2,049-4,096$ & 1 & $0.01 \%$ & $100.00 \%$ \\
\hline
\end{tabular}

The depth of contigs showing less than 5 copies of expression consist mostly of the unigene variation.

\section{Amino acid substitutions between two planarians}

The protein BLAST software identifies the conserved regions and the degrees of similarity between query and subject amino acid sequences. BLAST shows not only identical amino acids at a given position in the alignment, but also homologous substitutions, which are determined from the scoring matrix (Figure 5A). A method for calculating the identical match ratio (the number of identical matches divided by the sum of identical matches plus homologous substitutions) (Figure 5B) was applied to find strongly and weakly conserved proteins between the two planarians $D$. japonica and $S$. mediterranea. After comparative analysis of each unigene by TBLASTX, to obtain sufficient homologous pairs for the extraction, some filter options were applied to the results. Finally, a total of 3,177 pairs remained as homologous genes, and the top 15\% (high substitution) and the bottom 15\% (low substitution) of them regarding the identical match ratio (a total of 952 genes) were sorted into functional categories by RPS-BLAST analysis using the eukaryotic clusters of orthologous groups (KOG) database [49]. Of these, 843 (88.6\%) genes were classified into $4 \mathrm{KOG}$ categories with $24 \mathrm{KOG}$ functions. No genes were classified as 'Cell motility' KOG function.

Figure 6A shows the classified gene number and the $\log _{2}$ odds ratios between conserved and identical gene pairs. The ratio varied widely (from +2.66 to -2.51 ) according to the KOG function, as did the number of genes, and showed a linear gradient with little bias. In the functions 'Secondary metabolites biosynthesis, transport and catabolism' and 'Defense mechanisms', there were only conserved group genes, as indicated by the identical match ratio. Inspection of the KOG category classification (Figure 6B) showed that many conserved genes were concentrated in the 'Metabolism' category, while 'Information Storage and Processing' contained many identical genes. In contrast, genes that were classified into 'Defense mechanisms' and 'Cell 


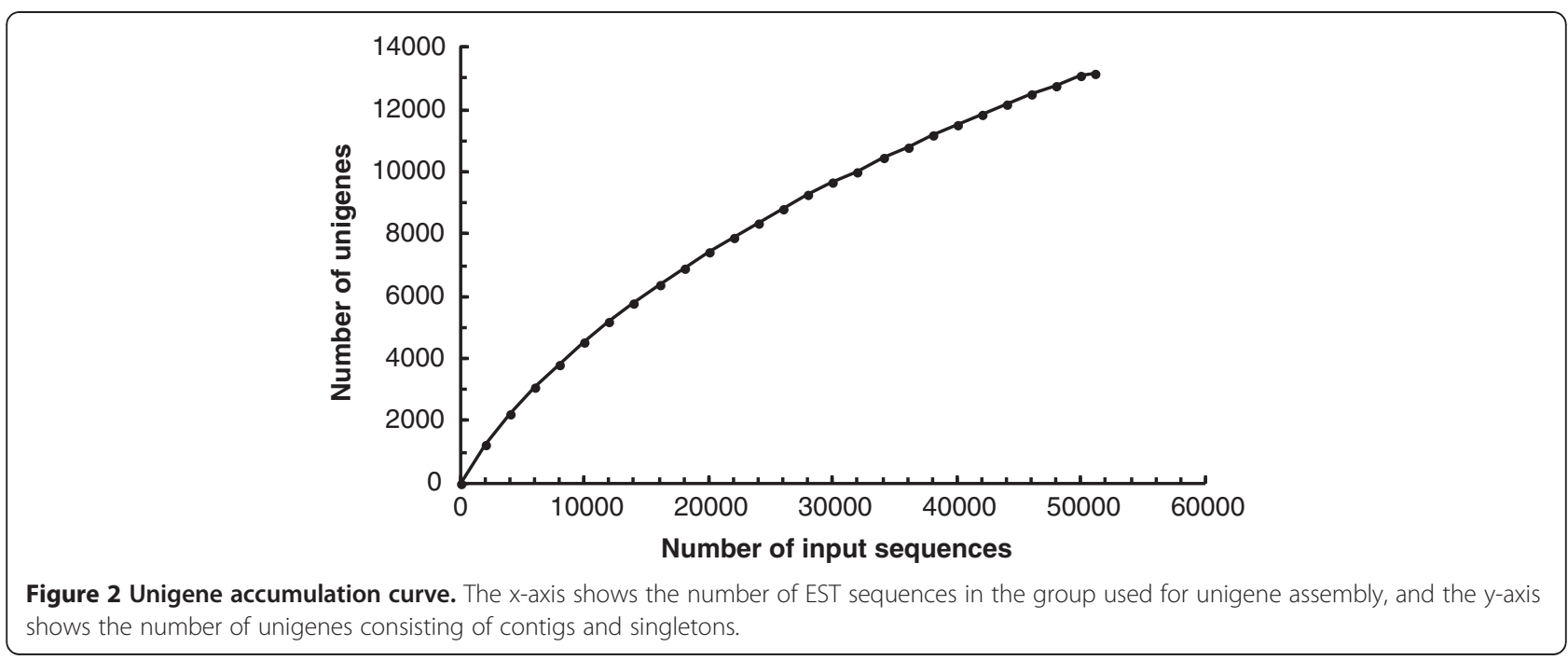

wall/membrane/envelope biogenesis' functions showed a low identical match ratio among genes in the 'Cellular Processes and Signaling' category. Additional file 2 displays examples of high-substitution-rate proteins between $D$. japonica and $S$. mediterranea for each category.

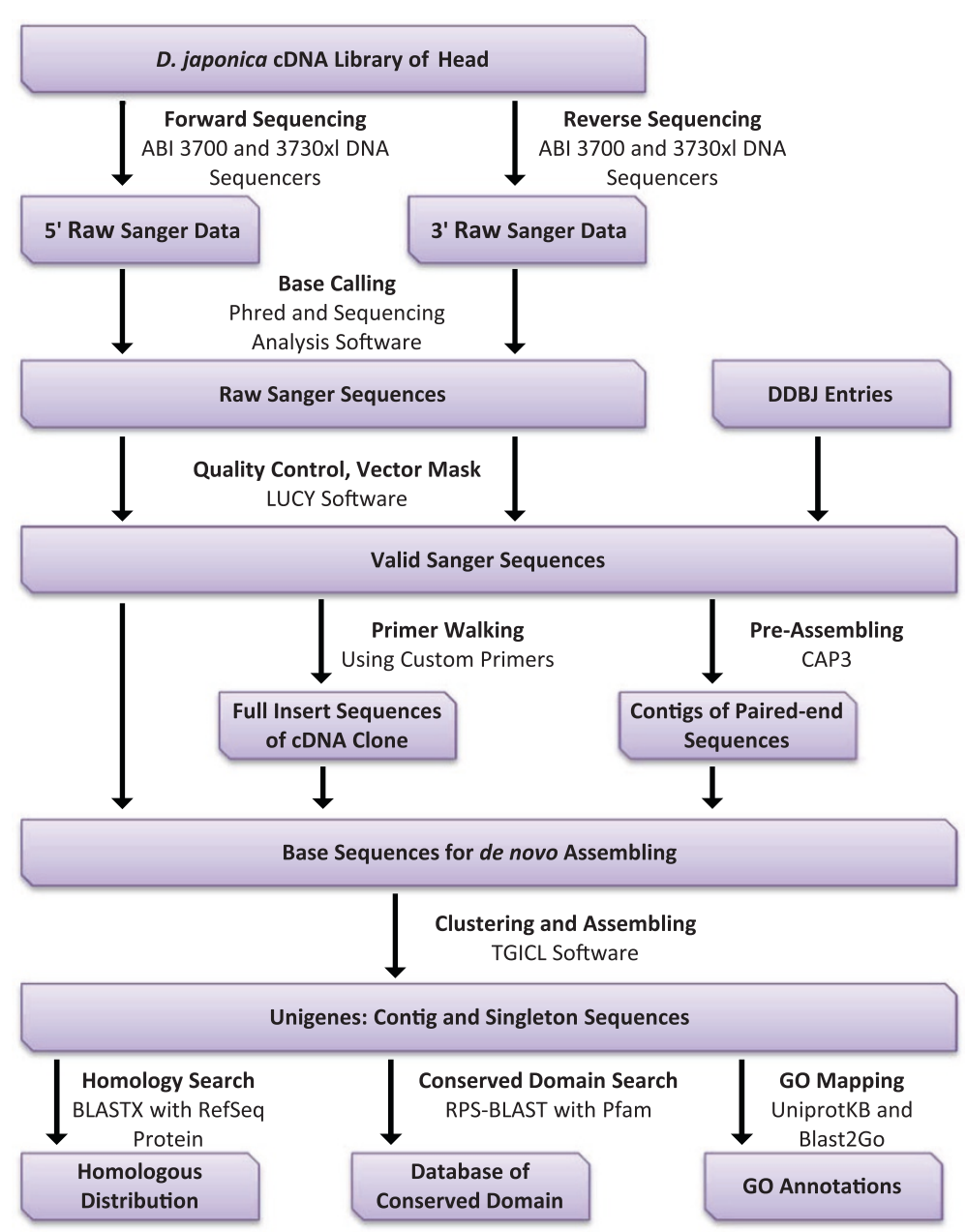

Figure 3 Flow chart for the generation and annotation of $D$. japonica unigenes. 


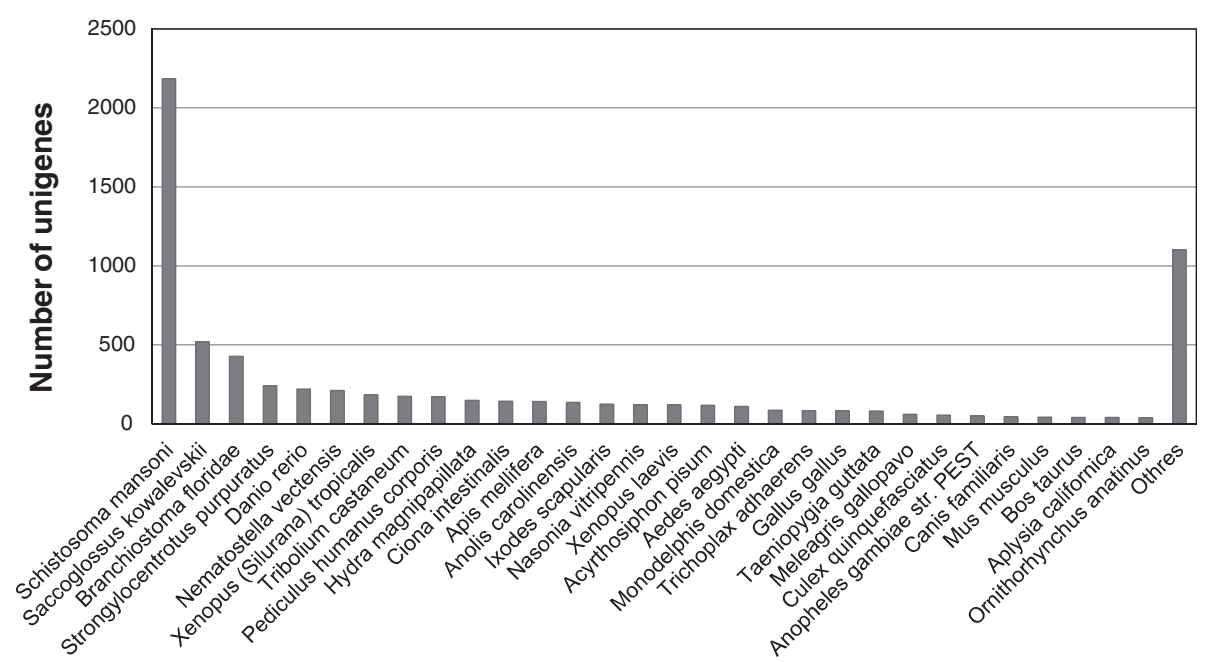

Figure 4 Species distribution of significant homologous matches of the unique sequences. A total of 7,334 sequences were hit with the RefSeq protein database using BLASTX with an E-value 1e-10. The top 30 species and number of sequences are shown.

\section{Extraction of the planarian CNS-development genes}

To obtain insight into the evolutionary origin of a functional brain, central nervous system (CNS)-development genes were extracted from the $D$. japonica unigenes using GO annotations as a common knowledge base. The category "CNS-development" was chosen here because we reasoned that the strong evolutionary/structural conservation of the planarian and higher animal brains implies conservation of many brain developmental pathways. Based on the results of BLASTX analysis against UniProtKB, each primary hit was defined as a putative planarian protein and function. The GO term 'central nervous system development' (GO:0007417) has 14 subcategories, each of which has a considerable number of subfamilies and terms. Because a protein which had multifunctions was mapped to each respective term separately, the total count of hits classed to CNSdevelopment genes was increased by such duplications. The classification analysis produced a total of 96 matches and 82 CNS-development genes, with 6 subcategories (Table 5). The most highly represented subcategory was 'brain development' (GO:0007420), with 68 matches, and the second- and third-most frequent were 'spinal cord development' (GO:0021510) and 'central nervous system neuron differentiation' (GO:0021953), with 10 and 8 matches, respectively. In addition, 4 matches were found for the subcategory 'ventral cord development'.

\section{Comparative analysis of CNS-development genes among platyhelminths}

Two types of schistosome genome dataset, the primary genome sequence and predicted protein sequences based on the genome sequence, and the primary genome sequence of $S$. mediterranea, were used for exploring the Platyhelminthes genes that are homologous with $D$. japonica CNS-development genes. The primary genome sequence provides evidence useful for distinguishing between genes with low expression and deleted genes. The predicted protein sequences were directly dependent on the computational process, and were not tested regarding whether they were supported by biological evidence of the gene expression, but contributed to the detection of genes that have small exons split by long intron regions. In the case of direct searching against primary genome sequences, the $D$. japonica unigenes were mapped by BLAT software [50] using the parameters of the six translation frames to compare the proteinprotein sequences. In addition, the predicted protein sequences were analyzed using the TBLASTN program. The use of translated nucleotide databases and translated nucleotide query enables absorption of the third codon position mutations, and therefore it is useful for comparison of evolutionarily distant genes. In these searches, if either one of the two scores exceeded the threshold, the matched gene was defined as conserved. A transcriptome-transcriptome analysis among platyhelminths was performed using TBLASTX rather than BLASTN for the same reason as described above.

The summary showed that the D. japonica CNSdevelopment genes were highly conserved among platyhelminths (Table 5). In the case of comparison with $S$. mediterranea, all of the 82 genes were detected in the genome sequence, and almost all of the genes (81/82) were found in the transcriptome data set obtained by next generation sequencing. In total, 75/82 (91\%) D. japonica CNS-development genes were conserved in the schistosome genome. Most of these genes were in 
Table 4 The top 40 Pfam domains and families in $D$. japonica unigenes

\begin{tabular}{|c|c|c|}
\hline Pfam_ID & Conserved Domain & Genes \\
\hline pfam00069 & Protein kinase domain & 307 \\
\hline pfam12796 & Ankyrin repeats & 101 \\
\hline pfam00076 & RNA recognition motif & 71 \\
\hline pfam00071 & Ras family & 62 \\
\hline pfam07690 & Major Facilitator Superfamily & 49 \\
\hline pfam07714 & Protein tyrosine kinase & 38 \\
\hline pfam00876 & Innexin & 34 \\
\hline pfam00443 & Ubiquitin carboxyl-terminal hydrolase & 33 \\
\hline pfam00067 & Cytochrome P450 & 32 \\
\hline pfam00270 & DEAD/DEAH box helicase & 29 \\
\hline pfam00102 & Protein-tyrosine phosphatase & 28 \\
\hline pfam00001 & $\begin{array}{l}7 \text { transmembrane receptor } \\
\text { (rhodopsin family) }\end{array}$ & 27 \\
\hline pfam00022 & Actin & 27 \\
\hline pfam00112 & Papain family cysteine protease & 27 \\
\hline pfam00350 & Dynamin family & 26 \\
\hline pfam00240 & Ubiquitin family & 23 \\
\hline pfam00335 & Tetraspanin family & 23 \\
\hline pfam11901 & Protein of unknown function (DUF3421) & 23 \\
\hline pfam03028 & $\begin{array}{l}\text { Dynein heavy chain and region } \\
\text { D6 of dynein motor }\end{array}$ & 22 \\
\hline pfam00226 & DnaJ domain & 21 \\
\hline pfam00271 & Helicase conserved C-terminal domain & 21 \\
\hline pfam00012 & Hsp70 protein & 20 \\
\hline pfam02931 & $\begin{array}{l}\text { Neurotransmitter-gated ion-channel } \\
\text { ligand binding domain }\end{array}$ & 20 \\
\hline pfam00153 & Mitochondrial carrier protein & 19 \\
\hline pfam00179 & Ubiquitin-conjugating enzyme & 19 \\
\hline pfam00620 & RhoGAP domain & 19 \\
\hline pfam01576 & Myosin tail & 19 \\
\hline pfam03953 & Tubulin C-terminal domain & 19 \\
\hline pfam00004 & $\begin{array}{l}\text { ATPase family associated with } \\
\text { various cellular activities }\end{array}$ & 16 \\
\hline pfam00017 & $\mathrm{SH} 2$ domain & 16 \\
\hline pfam00060 & Ligand-gated ion channel & 16 \\
\hline pfam00089 & Trypsin & 16 \\
\hline pfam00155 & Aminotransferase class I and II & 16 \\
\hline pfam00168 & C2 domain & 16 \\
\hline pfam01145 & SPFH domain/Band 7 family & 16 \\
\hline pfam00046 & Homeobox domain & 15 \\
\hline pfam00091 & Tubulin/FtsZ family, GTPase domain & 15 \\
\hline pfam00307 & Calponin homology $(\mathrm{CH})$ domain & 15 \\
\hline pfam00501 & AMP-binding enzyme & 15 \\
\hline pfam00782 & $\begin{array}{l}\text { Dual specificity phosphatase, } \\
\text { catalytic domain }\end{array}$ & 15 \\
\hline
\end{tabular}

\section{Discussion}

\section{D. japonica transcriptome}

We performed large scale $D$. japonica transcriptome analysis using non-normalized cDNA libraries constructed from head tissue to construct a transcriptome database for comparative genomics and studies of brain evolution. Compared with normalized cDNA libraries, in which the proportion of high-copy housekeeping genes is decreased, non-normalized cDNA libraries have many redundant transcripts, but they keep the information of the original expression levels and are expected to provide raw expression profiles [40]. Next generation sequencing is a powerful tool that has provided massive datasets for genome and transcriptome analysis, including some datasets for the $S$. mediterranea transcriptome [26-28]. However, for comparative analysis between two planarians, it is important to use long and gapless consensus sequences of conserved proteins. To obtain such sequences, next-generation sequencing is not always the best tool. For example, Roche 454 cannot correctly read homo-polymer sequences like AAAA or TTTT (and this is relevant because planarians are AT-rich organisms), and this limitation may cause many frame-shift errors in a gene sequence. Also, although Illumina HiSeq generates a large volume of reads, they are rather short, and this makes it difficult to obtain long and correct contig sequences without high quality reference information. The paired-end application is a useful way to link separated contigs, but long gaps often arise when there are no consensus sequences. In contrast, Sanger sequencing provides long, high-quality mRNA reads, which are important for comparative analysis using consensus sequences of conserved protein domains. Furthermore, long reads can help to distinguish between paralogues and alternative splicing variants, and thus are useful for transcriptome research of non-model organisms for which high-quality genomic information is lacking.

In this study, we obtained a total of 13,167 unigenes with $940.5 \mathrm{bp}$ average length as a result of de novo assembly using 54,752 newly acquired long Sanger sequences. Two types of pre-assembled reads, gapclosed sequences obtained by a primer walking method, and overlap-joined contigs from the same clone, contributed to extending the contig length. Additionally, many singletons that were unassembled ESTs also had sufficient length to identify the function. The histogram of 


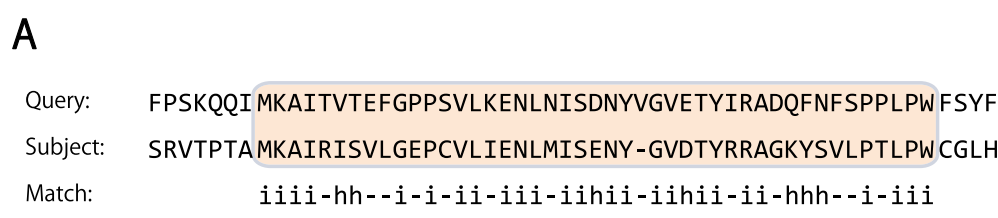

B

$$
\text { Identical match ratio }=\frac{\text { Identical matches }}{\text { Identical matches }+ \text { Homologous substitutions }}
$$

Figure 5 Algorithm for the identical match ratio calculation between conserved proteins. (A) Alignment output of Protein-BLAST. The colored box shows a conserved region between query and subject sequences defined by BLAST. Match type i and $h$ indicate identical matches and homologous substitutions, which are based on the BLOSUM62 matrix, and - means no similarity or a gap. (B) The equation used to calculate the identical match ratio. A large substitution ratio within a conserved region leads to a decreased identical match ratio, which indicates that a homologous pair exhibits a high rate of diversification. In the case of A, the identical match ratio is "0.78".

assembly statistics (Table 3) and functional annotations of the assembled unigenes, based on conserved domain search by RPS-BLAST (Table 4), indicated that we had built an encompassing and low-bias gene profile that provided enough information for comparative transcriptome analysis among two planarians and a schistosome. Regarding approaches to non-model organism transcriptomes, the algorithms applied and dataset selection are of the same importance as de novo assembling for finding new evolutionary events or pathways. Here, we report two different approaches to finding such events, not simply the acquisition of basic knowledge about the D. japonica transcriptome.

\section{Comparative analysis between two planarians}

The acquisitions of gene mutations and corresponding amino acid substitutions are not random events, but rather are affected by the pressure of natural selection. It is generally accepted that similar proteins with homologous substitutions share basic molecular functions in organisms [51]. The biotic features (lifestyle, ability to regenerate, and cell characteristics) of the two planarians studied here, $D$. japonica and S. mediterranea, are quite similar, and large numbers of their genes and their encoded amino acid sequences are well conserved. However, the nucleic acid sequences of many homologous genes have low similarity between these two planarians, and there are many genes containing homologous substitutions for amino acids in conserved regions, although the profiles and details remain unknown. For example, PIWI2 alignment shows $94 \%$ identical matches of amino acids over the entire sequence (Additional file 3). But in the case of GGT1, only 70\% of amino acids are the same, although the percentage rises to $88 \%$ if homologous substitutions are included (Additional file 4).

Based on the hypothesis that proteins with many substitutable amino acids could be candidates for members of gene groups that are able to undergo changes to accommodate to different environments, we developed a new method for detecting the fraction of substitutable amino acids within individual genes. To view the trends in functional groups of proteins rather than in each gene, we classified the results calculated by this method into functions and categories based on KOG annotation. The $\log _{2}$ ratio between the number of proteins with homologous substitutions and the number with identical matches revealed distinctive features of function and category (Figure 6). Although a very long time has passed since their divergence from their common ancestor, amino acids in proteins involved in basal mechanisms such as functions of the 'Information Storage and Processing' category and cellular structure-related functions 'Cytoskeleton' and 'Extracellular structures' have not undergone replacement even by amino acids that have similar biochemical properties, presumably as a result of selection pressure. By contrast, in the function 'Defense mechanisms', which is directly linked to an organism's environment, every gene mapped to this function displayed a high rate of substitution. Among the proteins in the category 'Metabolism', the energy metabolism functions 'Carbohydrate transport and metabolism' and 'Energy production and conversion' showed low rates of substitution, whereas genes related to digestion processes (lipid, nucleotide and amino acid digestion) had high rates of substitution, perhaps reflecting responsiveness to their feeding habitat. It is interesting that many accumulations of amino-acid substitutions were observed in proteins that were well conserved not only between the two planarians examined here, but among many species, and were expected to maintain their biological function (Additional file 2). Previous studies of schistosomes suggested that these animals are incapable of de novo synthesis of sterols or free fatty acids and must use precursors of fatty acids from the host $[19,52]$. It could be considered that the effects of selection pressure on metabolism-related genes are decreased in parasitic life, 


\begin{tabular}{|c|c|c|c|c|}
\hline $\begin{array}{l}\text { KOG } \\
\text { Code }\end{array}$ & KOG Functions & $\begin{array}{c}\text { Conserved } \\
\text { Protein }\end{array}$ & $\begin{array}{c}\text { Identical } \\
\text { Protein }\end{array}$ & $\begin{array}{c}\log _{2} \text { Ratio } \\
\text { (conserved } \\
\text { / identical) }\end{array}$ \\
\hline $\mathrm{Q}$ & Secondary metabolites biosynthesis, transport and catabolism & 12 & 0 & \\
\hline v & Defense mechanisms & 5 & 0 & * \\
\hline 1 & Lipid transport and metabolism & 19 & 3 & 2.66 \\
\hline $\mathrm{F}$ & Nucleotide transport and metabolism & 10 & 2 & 2.32 \\
\hline E & Amino acid transport and metabolism & 16 & 4 & 2.00 \\
\hline M & Cell wall/membrane/envelope biogenesis & 5 & 2 & 1.32 \\
\hline $\mathrm{P}$ & Inorganic ion transport and metabolism & 19 & 11 & 0.79 \\
\hline D & Cell cycle control, cell division, chromosome partitioning & 10 & 8 & 0.32 \\
\hline $\mathrm{Y}$ & Nuclear structure & 1 & 1 & 0.00 \\
\hline $\mathrm{H}$ & Coenzyme transport and metabolism & 1 & 1 & 0.00 \\
\hline $\mathrm{N}$ & Cell motility & 0 & 0 & - \\
\hline $\mathrm{T}$ & Signal transduction mechanisms & 72 & 73 & -0.02 \\
\hline $\mathrm{s}$ & Function unknown & 17 & 20 & -0.23 \\
\hline $\mathrm{L}$ & Replication, recombination and repair & 4 & 5 & -0.32 \\
\hline 0 & Posttranslational modification, protein turnover, chaperones & 34 & 45 & -0.40 \\
\hline G & Carbohydrate transport and metabolism & 9 & 13 & -0.53 \\
\hline $\mathrm{R}$ & General function prediction only & 38 & 55 & -0.53 \\
\hline $\mathrm{u}$ & Intracellular trafficking, secretion, and vesicular transport & 30 & 44 & -0.55 \\
\hline C & Energy production and conversion & 8 & 13 & -0.70 \\
\hline $\mathrm{J}$ & Translation, ribosomal structure and biogenesis & 15 & 30 & -1.00 \\
\hline w & Extracellular structures & 1 & 2 & -1.00 \\
\hline A & RNA processing and modification & 16 & 38 & -1.25 \\
\hline z & Cytoskeleton & 13 & 51 & -1.97 \\
\hline B & Chromatin structure and dynamics & 4 & 16 & -2.00 \\
\hline $\mathrm{K}$ & Transcription & 7 & 40 & -2.51 \\
\hline
\end{tabular}

B

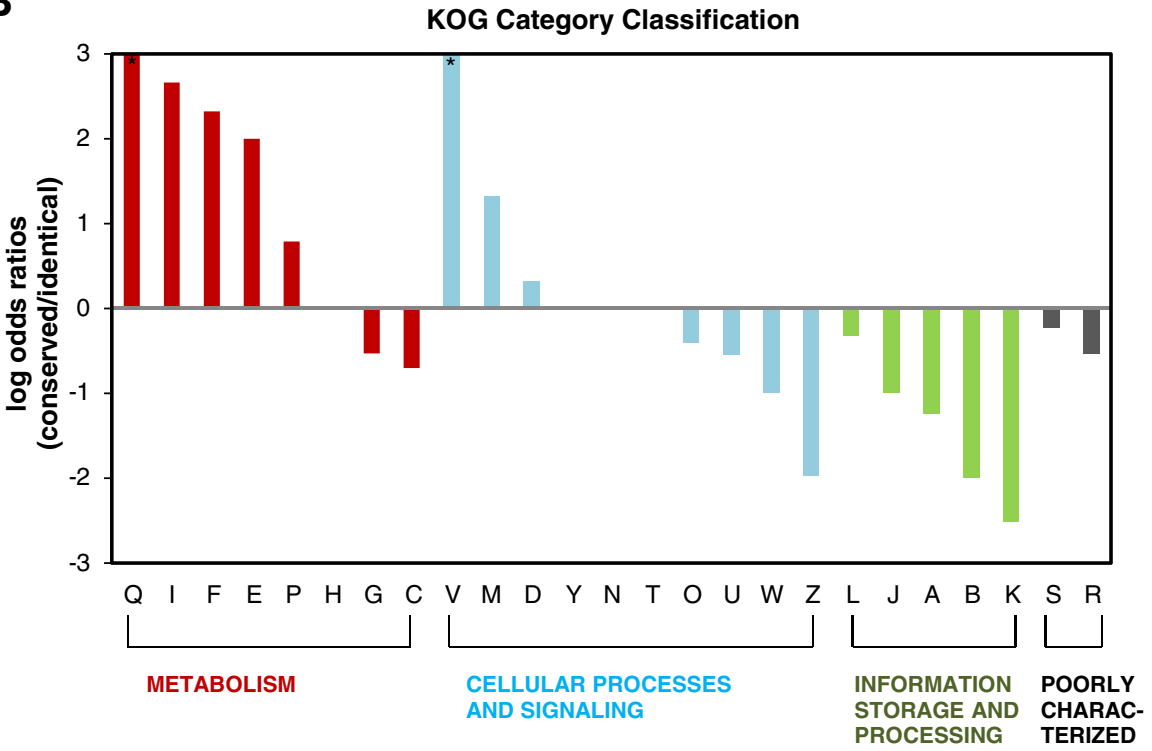

Figure 6 Classification of the planarian conserved/identical proteins using KOG annotation. (A) The definitions of conserved protein and identical protein were derived from the identical match ratio calculation using the BLOSUM62 substitution matrix and the conserved region between homologous proteins in the 2 planarian species which were predicted by protein BLAST. After conserved domain search using the KOG database, each gene was classified in accordance with KOG functions. The columns of Conserved and Identical proteins show the numbers of genes that were classified into each function. The heat plot shows the $\log _{2}$ conserved/identical match ratio, with red indicating a high proportion of proteins with substitutions and green indicating that the majority of proteins are identical for the indicated function. ${ }^{*}$ indicates a function that contained only conserved proteins (shown in red color). (B) KOG category classification shows obvious patterns that were clearly distinguishable for each category. Many relatively conserved genes were concentrated in 'Metabolism', whereas 'Information Storage and Processing' contained many identical genes. 
Table 5 Comparative analysis of $D$. japonica CNS development genes with $S$. mediterranea and the schistosoma

\begin{tabular}{|c|c|c|c|c|c|c|c|}
\hline \multirow[t]{2}{*}{ GO Term } & \multirow[t]{2}{*}{ D. japonica Unigenes } & \multirow[t]{2}{*}{ UniProt KB Homology } & \multirow{2}{*}{$\begin{array}{l}\text { UniProt } \\
\text { E-value }\end{array}$} & \multicolumn{2}{|c|}{ S. mediterranea } & \multicolumn{2}{|c|}{ Schistosoma } \\
\hline & & & & Genome & mRNA & Genome & mRNA \\
\hline \multirow[t]{4}{*}{ ventral cord development } & Dj_CL2868_001_b2 & Protein numb & $2.00 \mathrm{E}-68$ & + & + & + & + \\
\hline & Dj_CL0775_001_b2 & Ras-related protein Rac1 & $2.00 \mathrm{E}-85$ & + & + & + & + \\
\hline & Dj_aH_314_P04.full & Protein nubbin & $7.00 \mathrm{E}-21$ & + & + & + & \\
\hline & Dj_aH_000_00626HN.full & Zinc finger protein jing & $1.00 \mathrm{E}-12$ & + & + & + & \\
\hline \multirow[t]{27}{*}{ brain development } & Dj_CL0266_002_b2 & Dynein heavy chain, cytoplasmic & $0.00 E+00$ & + & + & + & + \\
\hline & Dj_aH_323_P16 & DNA topoisomerase 2-beta & 1.00E-129 & + & + & + & + \\
\hline & Dj_CL2992_001_b2 & Probable global transcription activator SNF2L1 & 1.00E-104 & + & + & + & + \\
\hline & Dj_CL0800_001_b2 & Transcriptional regulator ATRX & $5.00 \mathrm{E}-84$ & + & + & + & + \\
\hline & Dj_aH_133136_J24 & Myosin-10 & $2.00 \mathrm{E}-80$ & + & + & + & + \\
\hline & Dj_CL1927_001_b2 & Protein Wnt-4 & $3.00 \mathrm{E}-62$ & + & + & + & + \\
\hline & Dj_CL1142_001_b2 & Brain tumor protein & $5.00 \mathrm{E}-35$ & + & + & + & + \\
\hline & Dj_CL2438_001_b2 & Ubiquitin carboxyl-terminal hydrolase isozyme $L 5$ & $3.00 \mathrm{E}-72$ & + & + & + & + \\
\hline & Dj_CL1575_001_b2 & Alpha-soluble NSF attachment protein & $1.00 \mathrm{E}-77$ & + & + & + & + \\
\hline & Dj_aH_121124_O06 & cGMP-dependent protein kinase 1 & 4.00E-81 & + & + & + & + \\
\hline & Dj_aH_203_F09 & Neurofibromin & $2.00 \mathrm{E}-40$ & + & + & + & + \\
\hline & Dj_aH_517_H15.double & Receptor tyrosine-protein kinase erbB-4 & $3.00 \mathrm{E}-83$ & + & + & + & + \\
\hline & Dj_aH_526_D23.double & Hypoxanthine-guanine phosphoribosyltransferase & 4.00E-61 & + & + & + & + \\
\hline & Dj_aH_214_D06.full & Homeobox protein SIX3 & $2.00 E-90$ & + & + & + & + \\
\hline & Dj_aH_202_C21 & Plasma membrane calcium-transporting ATPase 3 & $8.00 \mathrm{E}-47$ & + & + & + & + \\
\hline & Dj_CL0788_001_b2 & Neural cell adhesion molecule 1 & $5.00 \mathrm{E}-18$ & + & + & + & + \\
\hline & Dj_aH_204_E12 & Protein kinase $C$ iota type & $1.00 \mathrm{E}-49$ & + & + & + & + \\
\hline & Dj_CL3335_001_b2 & Nuclear factor 1 B-type & 4.00E-14 & + & + & + & + \\
\hline & Dj_aH_307_L04.rev & cGMP-dependent protein kinase 1 & $8.00 \mathrm{E}-55$ & + & + & + & + \\
\hline & Dj_CL3457_001_b2 & RNA binding protein fox-1 homolog 1 & $5.00 \mathrm{E}-33$ & + & + & + & + \\
\hline & Dj_CL1765_001_b2 & Zinc finger protein ZIC 2 & $2.00 \mathrm{E}-73$ & + & + & + & + \\
\hline & Dj_aH_503_H01 & Epidermal growth factor receptor & $9.00 \mathrm{E}-38$ & + & + & + & + \\
\hline & Dj_aH_511_L17 & Tubby-related protein 3 & $2.00 \mathrm{E}-44$ & + & + & + & + \\
\hline & Dj_CL1678_001_b2 & $\begin{array}{l}\text { NADH dehydrogenase [ubiquinone] } \\
\text { iron-sulfur protein } 4 \text {, mitochondrial }\end{array}$ & $2.00 \mathrm{E}-35$ & + & + & + & + \\
\hline & Dj_CL2162_001_b2 & Menin & $1.00 \mathrm{E}-37$ & + & + & + & + \\
\hline & Dj_CL3785_001_b2 & Excitatory amino acid transporter 2 & $5.00 \mathrm{E}-28$ & + & + & + & + \\
\hline & Dj_aH_514_N16 & DNA topoisomerase 2-beta & $2.00 E-33$ & + & + & + & + \\
\hline
\end{tabular}


Table 5 Comparative analysis of $\boldsymbol{D}$. japonica CNS development genes with $\boldsymbol{S}$. mediterranea and the schistosoma (Continued)

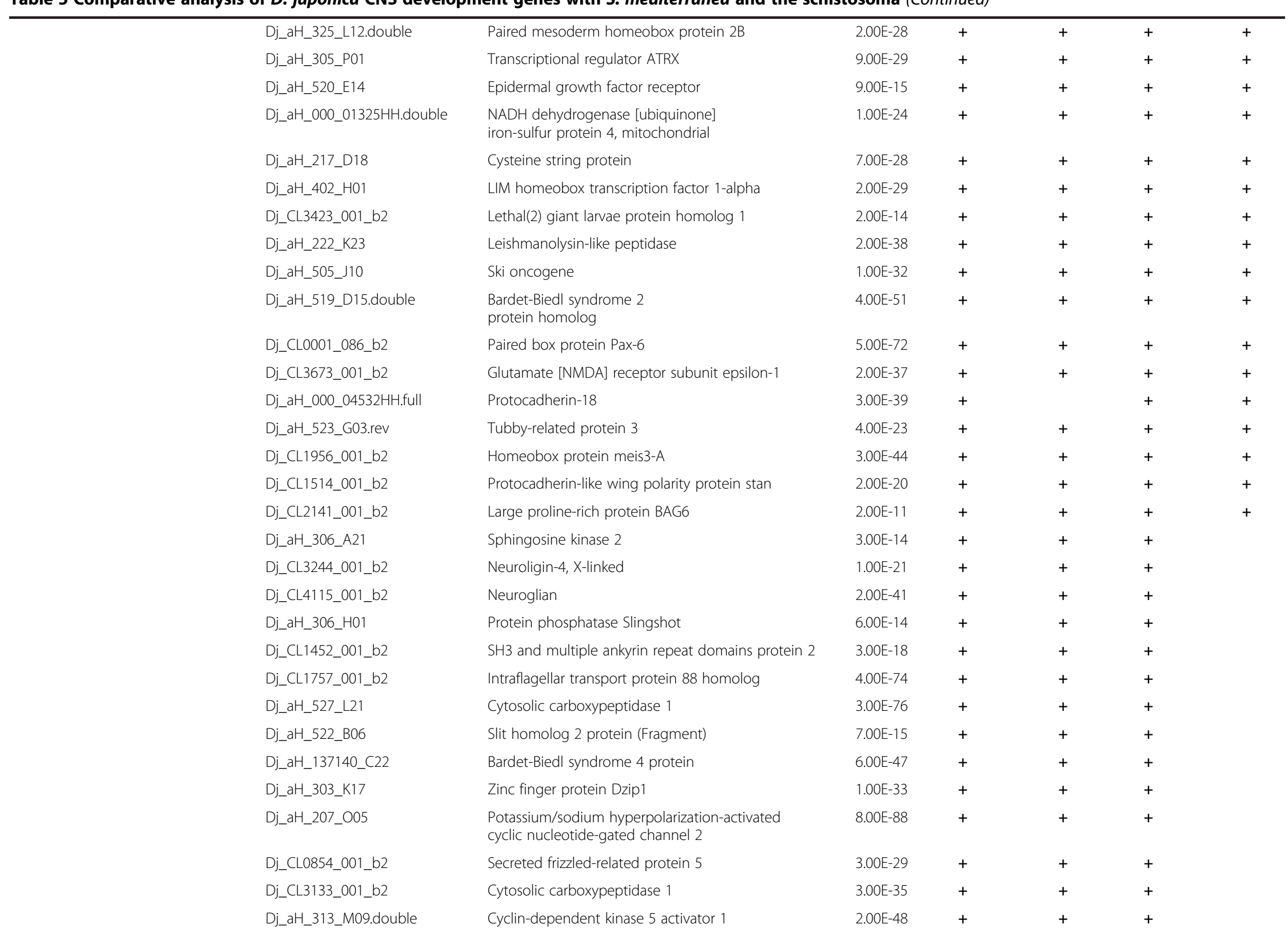


Table 5 Comparative analysis of $\boldsymbol{D}$. japonica CNS development genes with $\boldsymbol{S}$. mediterranea and the schistosoma (Continued)

\begin{tabular}{|c|c|c|c|c|c|c|c|}
\hline & Dj_CL0876_001_b2 & Sodium/calcium exchanger 1 & $1.00 \mathrm{E}-161$ & + & + & + & \\
\hline & Dj_aH_303_F09 & Frizzled-8 & $1.00 \mathrm{E}-21$ & + & + & + & \\
\hline & Dj_CL4143_001_b2 & Intraflagellar transport protein 88 homolog & $2.00 \mathrm{E}-81$ & + & + & + & \\
\hline & Dj_aH_530_O19 & Paired box protein Pax-6 & $9.00 \mathrm{E}-55$ & + & + & + & \\
\hline & Dj_aH_007_F21 & Protein Hook homolog 3 & $6.00 \mathrm{E}-13$ & + & + & & \\
\hline & Dj_aH_309_N15.double & Dixin & $6.00 \mathrm{E}-11$ & + & + & & \\
\hline & Dj_CL4393_001_b2 & Endothelin-converting enzyme 2 & $7.00 \mathrm{E}-34$ & + & + & & \\
\hline & Dj_aH_325_L06 & Centrosomal protein of $290 \mathrm{kDa}$ & $3.00 \mathrm{E}-31$ & + & + & & \\
\hline & Dj_CL0234_001_b2 & Reticulon-4 & $2.00 \mathrm{E}-13$ & + & + & & \\
\hline & Dj_aH_518_F04.double & Ceroid-lipofuscinosis neuronal protein 5 & $2.00 \mathrm{E}-74$ & + & + & & \\
\hline \multirow[t]{10}{*}{ spinal cord development } & Dj_aH_203_F09 & Neurofibromin & $2.00 \mathrm{E}-40$ & + & + & + & + \\
\hline & Dj_aH_000_02581HH & Calpain-A & $1.00 \mathrm{E}-51$ & + & + & + & + \\
\hline & Dj_aH_502_D11 & Calpain-A & $2.00 \mathrm{E}-67$ & + & + & + & + \\
\hline & Dj_aH_511_L17 & Tubby-related protein 3 & $2.00 \mathrm{E}-44$ & + & + & + & + \\
\hline & Dj_CL3713_001_b2 & Suppressor of fused homolog & $2.00 \mathrm{E}-21$ & + & + & + & + \\
\hline & Dj_aH_000_01210HH.full & Suppressor of fused homolog & $3.00 \mathrm{E}-15$ & + & + & + & + \\
\hline & Dj_CL3673_001_b2 & Glutamate [NMDA] receptor subunit epsilon-1 & $2.00 \mathrm{E}-37$ & + & + & + & + \\
\hline & Dj_aH_523_G03.rev & Tubby-related protein 3 & 4.00E-23 & + & + & + & + \\
\hline & Dj_aH_522_B06 & Slit homolog 2 protein (Fragment) & 7.00E-15 & + & + & + & \\
\hline & Dj_aH_000_03614HH & DNA-binding protein SMUBP-2 & 4.00E-23 & + & + & & \\
\hline \multirow{8}{*}{$\begin{array}{l}\text { central nervous system } \\
\text { neuron differentiation }\end{array}$} & Dj_CL2485_001_b2 & Spastin & $1.00 \mathrm{E}-83$ & + & + & + & + \\
\hline & Dj_aH_526_D23.double & Hypoxanthine-guanine phosphoribosyltransferase & 4.00E-61 & + & + & + & + \\
\hline & Dj_aH_511_L17 & Tubby-related protein 3 & $2.00 \mathrm{E}-44$ & + & + & + & + \\
\hline & Dj_aH_402_H01 & LIM homeobox transcription factor 1-alpha & $2.00 \mathrm{E}-29$ & + & + & + & + \\
\hline & Dj_aH_523_G03.rev & Tubby-related protein 3 & 4.00E-23 & + & + & + & + \\
\hline & Dj_aH_527_L21 & Cytosolic carboxypeptidase 1 & $3.00 \mathrm{E}-76$ & + & + & + & \\
\hline & Dj_CL3133_001_b2 & Cytosolic carboxypeptidase 1 & $3.00 \mathrm{E}-35$ & + & + & + & \\
\hline & Dj_aH_000_03614HH & DNA-binding protein SMUBP-2 & $4.00 \mathrm{E}-23$ & + & + & & \\
\hline \multirow[t]{3}{*}{ astrocyte differentiation } & Dj_aH_203_F09 & Neurofibromin & $2.00 \mathrm{E}-40$ & + & + & + & + \\
\hline & Dj_CL0341_002_b2 & Porphobilinogen deaminase & $4.00 \mathrm{E}-69$ & + & + & + & + \\
\hline & Dj_CL0341_001_b2 & Porphobilinogen deaminase & $2.00 \mathrm{E}-64$ & + & + & + & + \\
\hline \multirow[t]{3}{*}{ oligodendrocyte differentiation } & Dj_aH_203_F09 & Neurofibromin & $2.00 \mathrm{E}-40$ & + & + & + & + \\
\hline & Dj_aH_513_H15.rev & Exocyst complex component 4 & $7.00 \mathrm{E}-18$ & + & + & + & + \\
\hline & Dj_CL1495_001_b2 & Translation initiation factor elF-2B subunit delta & 4.00E-42 & + & + & + & + \\
\hline
\end{tabular}


because an appropriate nutritional environment is provided by the host. These previously reported results support our hypothesis that, in addition to selective pressure from the environment, the potential of genes to accommodate substitutions is also an important factor in evolution.

\section{Evolutionary conservation of CNS-development genes}

As mentioned above, platyhelminths are considered to be primitive animals that possess a functional CNS closely related to the evolutionary origin of the CNS. The D. japonica CNS is composed of an anterior cephalic ganglion and ventral nerve cords, which are morphologically distinguishable structures. Planarians can sense light and chemical signals transmitted through their eyes and chemosensors, respectively, to their brain, and show different behaviors according to the type of signal.

In addition the partial results of previous transcriptome analysis, we previously reported several genes specifically expressed in the CNS, such as synaptotagmin, prohormone convertase 2, and netrin [7,9,34]. But, as compared with model organisms, the gene information for platyhelminths is very limited, and this makes it difficult to perform whole transcriptome comparison. For this reason we used Gene Ontology and the category "CNS-development", which is based on information across many species, including vertebrates and non-vertebrates. We think this annotation can serve well as a common platform for comparing and annotating among platyhelminths. Both the functionality and complexity of the planarian CNS are supported by our identification of 82 D. japonica genes related to CNS development, based on the Gene Ontology and UniProtKB knowledge base. Homology search with $S$. mediterranea showed that the genes are quite highly conserved between these two planarian species. All of the 82 genes were found in the $S$. mediterranea genome sequence and almost all of these genes $(81 / 82)$ were found in the $S$. mediterranea transcriptome data set derived by next generation sequencing. This number of CNS-development-related genes is not much lower than that in model organisms known to have highly functional brains, namely, D. melanogaster (228), D. rerio (285), G. gallus (129) and $M$. musculus (487) [35]. In addition, these numbers are clearly larger than the number of CNS-developmentrelated genes in C. elegans (6), which may have lost a complex CNS, and suggest the possibility that the planarian has a functional brain at not only the developmental level but also the genomic level.

The CNS of S. mansoni consists of a central ganglion, six pairs of main nerve trunks, and longitudinal nerve cords, which extend along the length of the body [4]. Additionally, six different types of sensory papillae are known, and are considered to be valuable structures for penetration and navigation through the vasculature in the body of the host. Using the predicted protein sequences of the schistosome and performing an exhaustive search of all possible CNS-development genes, 75 homologs of the 82 genes in $D$. japonica were successfully detected. This result indicates that the planarian CNS-development genes already existed before the divergence of planarians and schistosomes from their last common ancestor. Interestingly, expression of about one-third of the CNS genes was not observed in the schistosome Unigene database, which was built using transcript sequences. Because the schistosome unigenes were constructed from 7 different developmental stages, 1,611 libraries, and 152,704 sequences, their completeness is considered to be extremely high, and therefore these CNS-development genes not observed in this schistosome database can be concluded to have extremely low or no expression. It is possible that, in contrast to the free-living lifestyle of planarians, the parasitic life of schistosomes resulted in selective degeneration of unnecessary genes in schistosomes. The features of the brain are determined to a large degree by the differential regulation of the transcriptome during an animal's life cycle. Schistosomes not only inhabit various tissues of their intermediate and definitive hosts, but also traverse freshwater environments to change hosts. Viewed in this light, it might have been expected that the schistosome would have had more gene components related to the CNS, but instead it showed a reduced number of such genes. This might be because planarians face more complex circumstances than schistosomes regarding enemies or climate throughout their lifetime, or because schistosomes construct complicated components using more limited gene sets. Further studies will be needed to clarify the relation between gene diversification and external factors in organisms' environments. To validate possible scenarios of planarian CNS evolution, this database will be valuable for the identification of relevant genes. More extensive analyses of genes and genomic resources will be needed to better understand the functions and evolution of the CNS.

\section{Conclusions}

We have produced 54,752 high-quality EST reads from a head library of the planarian $D$. japonica, and de novo assembly analysis of these ESTs produced 13,167 unigene sequences. Similarity search against public databases and conserved domain analysis of predicted protein sequences indicated that this dataset is a useful resource for comparative transcriptome studies. Comparison of homologous genes between two planarian species led us to hypothesize that not only the pressure of natural selection but also the potential of genes is 
important for an acceleration of the accumulation of amino-acid substitutions, a hypothesis that is supported by previous studies showing that schistosomes are defective in lipid metabolism.

A total of 82 planarian CNS-development genes were extracted using Gene Ontology annotation, and this result suggested the possibility that the planarian has a functional brain both developmentally and genetically. Mapping of these genes onto the schistosome genome showed that the $91 \%$ of the planarian CNS-development genes were conserved within the schistosome genome. However, approximately one-third of the planarian CNS genes were not expressed in the schistosome. These analyses suggest that the establishment of the planarian CNS occurred before the divergence of planarians from their common ancestor with schistosomes, but that these two genuses subsequently diversified to adapt to their differing circumstances regarding the complexity needed for a free versus a parasitic life. This database of the $D$. japonica transcriptome constructed here provides an important resource not only for planarian research, but also for comparative analyses of the CNS.

\section{Methods}

\section{Animal materials}

An asexual clonal strain of the planarian Dugesia japonica derived from the Iruma River in Gifu prefecture, Japan, was used. This strain is named the GI strain. Intact animals were maintained in autoclaved tap water at $22-24{ }^{\circ} \mathrm{C}$. More than 500 planarians of length $5-7 \mathrm{~mm}$ that had starved for 7-10 days were used in this study. After amputation at the prepharyngeal region under a phase-contrast microscope, the head fragments were collected to construct the head cDNA library.

\section{cDNA library construction and DNA sequencing}

PolyA + RNAs were isolated from the head fragments and cloned into Uni-ZAP XR vector (Stratagene) according to the manufacturer's instructions. Using a Gigapack III Gold Cloning kit (Stratagene), the vectorcontaining cDNAs were packaged into lambda phage. The clones were converted into pBluescript SK(-) phagemids, and transformed into XL1-Blue MRF strain (Stratagene). The bacterial colonies were randomly picked using a colony picker QPix (GENETIX), and were grown overnight with ampicillin. The template DNAs for the 000-140 series (Table 1) were prepared using MultiScreen-NA and FB plates (Millipore). In the case of the 201-530 series, the library clone DNAs were amplified using the TempliPhi reaction, based on $\$ 29$ rolling circle replication of DNA (GE Healthcare). The sequencing reaction was performed using a BigDye terminator v.3.1 cycle sequencing kit (Life Technologies). The primers used in the reaction were SK and T3 for the forward direction, and M13 for the reverse direction. The sequencing reaction products were analyzed using a PRISM 3700 and 3730xl DNA analyzer (Life Technologies). The convention for naming of EST sequences is: [Library prefix]_[Plate number]_[ID]. The sequence name extensions, no-extension, '.rev', '.double' and 'ffull', mean forward-read, reverse-read, pairedassembly contig and gap-closed sequence, respectively. Dj_CL means contig sequence.

\section{Sequence validation}

The base calling for 000-140 series sequences was processed using Phred software, and other series were base called using Sequencing Analysis Software ver.5.2 (Life Technologies) with KB Basecaller (Life Technologies). After base calling, lower quality regions and vector sequences were trimmed using LUCY software (ver.1.19p) [53] with quality threshold of 0.01. Full-insert cDNA sequences were obtained by a primer-walking sequencing method until the sequence of both edges of the insert had been determined.

\section{De novo assembly}

Before whole de novo assembly, we used CAP3 software (ver. 04/15/05) to assemble the 5'- and 3'-end sequences of the same clone in the ESTs. In addition, 918 eye and 6,444 head EST entries were obtained from DDBJ (Additional file 1). To construct unigene sequences, all resources for EST sequences were clustered and assembled based on sequence similarity to generate a consensus sequence using TGICL software (ver. 2.1) with '-n 10000 -p 85 -1 60 -v 40' parameters.

\section{Homology and conserved domain search of $D$. japonica unigenes}

A survey of taxonomic distribution was conducted by matching the EST unigenes to the RefSeq protein database (Jun 5, 2011) using BLASTX software (ver. 2.2.23) with 1e-10 threshold. Only the top hit and the information on species were extracted and totaled from those results. Protein domain searches were performed with RPS-BLAST software (ver. 2.2.23) against the Pfam database (ver. 25.0) using the best hit with an E-value $<1 \mathrm{e}-10$.

\section{Classification of identical/conserved proteins using KOG annotation}

The evolutionarily shared gene pairs and the conserved regions between two planarians, D. japonica and S. mediterranea, were searched using the TBLASTX program against $S$. mediterranea unigenes (Build \#4) with the following filter options: BLOSUM62 substitution matrix, sequence length of $D$. japonica unigene $\geqq 600 \mathrm{bp}, 1 \mathrm{e}-30$ threshold and size of conserved region $\geqq 80 \mathrm{bp}$. Each conserved region reported by TBLASTX was analyzed to 
measure the identical match ratio (Figure 5) to determine whether the protein was a high- or low-substitution protein. The KOG database and RPS-BLAST software were used to classify the genes with E-value less than $1 \mathrm{e}-10$ into KOG functions and categories.

\section{Gene ontology classification}

To obtain reliable annotation for GO classification, we chose the UniProtKB/Swiss-Prot database (release 2011_06), which is a high-quality manually annotated and non-redundant protein sequence dataset. After BLASTX analysis with 1e-10 threshold, the top BLAST hit was used as a putative protein name of the input unigene sequence. Ontologies of the UniProt knowledge base were used for the conversion of the protein to GO terms, and GO slim digestion was performed to get a broad overview of the ontology content without the details of the specific segmentalized terms.

\section{Exhaustive comparative analysis of $D$. japonica CNS- development genes with $S$. mediterranea and schistosome genes}

Using the previous GO annotations of the unigenes, the genes that had GO term 'central nervous system development' (GO:0007417) or its 14 subcategories were defined as CNS-development genes. The genes that were defined by descendant terms of the subcategories of CNS development were added to the ancestral category to clarify the composition of planarian CNS genes. Comparison of $D$. japonica unigenes and the schistosome genome was performed using 2 pairs of software and the schistosome database with 1e-10 threshold: TBLASX (ver. 2.2.23) with the predicted protein (ver. 4) database [54], and BLAT software (ver. 3.4) with super contigs of genome sequences (ver. 3.1), respectively. If either one passed the threshold, the gene was defined as evolutionarily conserved. In cases of comparison of gene expression between $D$. japonica and the schistosome, TBLASTN (ver. 2.2.23) software and the schistosome unigenes (Build \#19) were used and the same threshold was set for comparison. The same methods as those used for the schistosome were applied to comparative analysis of $D$. japonica with $S$. mediterranea using threshold1e-30, the super contigs of genome sequences (ver. 3.1) [55] and transcriptome resources [26,27].

\section{Additional files}

Additional file 1: 7,362 DDBJ entries registered by previous research.

Additional file 2: Examples of high-substitution proteins between $D$. japonica and S. mediterranea.

Additional file 3: Alignment of $D$. japonica and S. mediterranea PIWI2.
Additional file 4: Alignment of $D$. japonica and S. mediterranea GGT1.

\section{Abbreviations}

cDNA: Complementary DNA; CNS: Central nervous system; EST: Expressed sequence tag; FACS: Fluorescence activated cell sorting; GO: Gene ontology; KOG: Eukaryotic clusters of orthologous groups; qRT-PCR: Quantitative reverse transcription polymerase chain reaction; RefSeq: NCBI reference sequence.

\section{Competing interests}

The authors declare that they have no competing interests.

\section{Authors' contributions}

ON performed bioinformatics analysis and wrote the manuscript. $\mathrm{YH}$ performed CDNA library cloning and DNA sequencing. HT designed the system for large scale DNA sequencing. KA coordinated the EST project and designed the study. All authors read and approved the final manuscript.

\section{Acknowledgements}

We thank Dr. Elizabeth Nakajima for critical reading of the manuscript and Dr. Takuya Imamura for many useful discussions. We also thank members of the Genome Resource and Analysis Unit, RIKEN CDB, and members of the Global COE Program: Evolution and Biodiversity, Kyoto University, for helpful comments and discussions. This study was supported in part by the Frontier Research Program, a Grant-in-Aid for Global COE Program A06, and a Grantin-Aid for Creative Scientific Research from the Ministry of Education, Culture, Sports, Science and Technology of Japan.

\section{Author details}

'Department of Biophysics and Global COE Program, Graduate School of Science, Kyoto University, Kitashirakawa-Oiwake, Sakyo-ku, Kyoto, Japan. ${ }^{2}$ Genome Resource and Analysis Unit, RIKEN Center for Developmental Biology, 2-2-3 Minatojima-Minamimachi, Chuo-ku, Kobe, Japan. ${ }^{3}$ Functional Probe Research Laboratory, RIKEN Center for Molecular Imaging Science, 6-7-3 Minatojima-Minamimachi, Chuo-ku, Kobe, Japan. ${ }^{4}$ LSA System Development Unit, RIKEN Omics Science Center, 1-7-22 Suehiro-cho, Tsurumi-ku, Yokohama, Japan.

Received: 9 December 2011 Accepted: 4 June 2012

Published: 29 June 2012

\section{References}

1. Kawakatsu M, Oki I, Tamura S: Taxonomy and geographical distribution of Dugesia japonica and D. ryukyuensis in the Far East. Hydrobiologia 1995, 305:55-61.

2. Umesono $Y$, Agata K: Evolution and regeneration of the planarian central nervous system. Dev Growth Differ 2009, 51:185-195.

3. Halton DW, Gustafsson MKS: Functional morphology of the platyhelminth nervous system. Parasitology 1996, 113:S47-S72.

4. Dorsey $\mathrm{CH}$, Cousin CE, Lewis FA, Stirewalt MA: Ultrastructure of the Schistosoma mansoni cercaria. Micron 2002, 33:279-323.

5. Umesono Y, Watanabe K, Agata K: A planarian orthopedia homolog is specifically expressed in the branch region of both the mature and regenerating brain. Dev Growth Differ 1997, 39:723-727.

6. Okamoto K, Takeuchi K, Agata K: Neural projections in planarian brain revealed by fluorescent dye tracing. Zool Sci 2005, 22:535-546.

7. Tazaki A, Gaudieri S, Ikeo K, Gojobori T, Watanabe K, Agata K: Neural network in planarian revealed by an antibody against planarian synaptotagmin homologue. Biochem Biophys Res Commun 1999, 260:426-432.

8. Sakai F, Agata K, Orii H, Watanabe K: Organization and regeneration ability of spontaneous supernumerary eyes in planarians: eye regeneration field and pathway selection by optic nerves. Zoolog Sci 2000, 17:375-381.

9. Agata K, Soejima Y, Kato K, Kobayashi C, Umesono Y, Watanabe K: Structure of the planarian central nervous system (CNS) revealed by neuronal cell markers. Zool Sci 1998, 15:433-440.

10. Coward SJ, Johannes RE: Amino Acid Che-moreception by the Planarian Dugesia dorotocephala. Comp Biochem Physiol 1969, 29:1475-1478. 
11. Pigon A, Morita M, Best JB: Cephalic mechanism for social control of fissioning in planarians. II. Localization and identification of the receptors by electron micrographic and ablation studies. J Neurobiol 1974, 5:443-462.

12. Inoue $T$, Kumamoto $H$, Okamoto $K$, Umesono $Y$, Sakai $M$, Sánchez Alvarado A, Agata K: Morphological and functional recovery of the planarian photosensing system during head regeneration. Zool SCi 2004, 21:275-283.

13. Agata K, Watanabe K: Molecular and cellular aspects of planarian regeneration. Semin Cell Dev Biol 1999, 10:377-383.

14. Newmark PA, Sánchez Alvarado A: Bromodeoxyuridine specifically labels the regenerative stem cells of planarians. Dev Biol 2000, 220:142-153.

15. Shibata N, Rouhana L, Agata K: Cellular and molecular dissection of pluripotent adult somatic stem cells in planarians. Dev Growth Differ 2010, 52:27-41.

16. Sánchez Alvarado A, Newmark PA: Double-stranded RNA specifically disrupts gene expression during planarian regeneration. Proc Natl Acad Sci USA 1999, 96:5049-5054.

17. Hayashi T, Asami M, Higuchi S, Shibata N, Agata K: Isolation of planarian X-ray-sensitive stem cells by fluorescence activated cell sorting. Dev Growth Differ 2006, 48:371-380.

18. Hayashi T, Shibata N, Okumura R, Kudome T, Nishimura O, Tarui H, Agata K: Single-cell gene profiling of planarian stem cells using fluorescent activated cell sorting and its "index sorting" function for stem cell research. Dev Growth Differ 2010, 52:131-144.

19. Berriman M, Haas BJ, LoVerde PT, Wilson RA, Dillon GP, Cerqueira GC, Mashiyama ST, Al-Lazikani B, Andrade LF, Ashton PD, Aslett MA, Bartholomeu DC, Blandin G, Caffrey CR, Coghlan A, Coulson R, Day TA, Delcher A, DeMarco R, Djikeng A, Eyre T, Gamble JA, Ghedin E, Gu Y, Hertz-Fowler C, Hirai H, Hirai Y, Houston R, Ivens A, Johnston DA, Lacerda D, Macedo CD, McVeigh P, Ning Z, Oliveira G, Overington JP, Parkhill J, Pertea M, Pierce RJ, Protasio AV, Quail MA, Rajandream MA, Rogers J, Sajid M, Salzberg SL, Stanke M, Tivey AR, White O, Williams DL, Wortman J, Wu W, Zamanian M, Zerlotini A, Fraser-Liggett CM, Barrell BG, El-Sayed NM: The genome of the blood fluke Schistosoma mansoni. Nature 2009, 460:352-358.

20. Robb SM, Ross E, Sánchez Alvarado A: SmedGD: the Schmidtea mediterranea genome database. Nucleic Acids Res 2008, 36:D599-D606.

21. Verjovski-Almeida S, DeMarco R, Martins EA, Guimarães PE, Ojopi EP, Paquola AC, Piazza JP, Nishiyama MY Jr, Kitajima JP, Adamson RE, Ashton PD, Bonaldo MF, Coulson PS, Dillon GP, Farias LP, Gregorio SP, Ho PL, Leite RA, Malaquias LC, Marques RC, Miyasato PA, Nascimento AL, Ohlweiler FP, Reis EM, Ribeiro MA, Sá RG, Stukart GC, Soares MB, Gargioni C, Kawano T, Rodrigues V, Madeira AM, Wilson RA, Menck CF, Setubal JC, Leite LC, Dias-Neto E: Transcriptome analysis of the acoelomate human parasite Schistosoma mansoni. Nat Genet 2003, 35:148-157.

22. Sánchez Alvarado A, Newmark PA, Robb SM, Juste R: The Schmidtea mediterranea database as a molecular resource for studying platyhelminthes, stem cells and regeneration. Development 2002, 129:5659-5665.

23. Zayas RM, Hernandez A, Habermann B, Wang Y, Stary JM, Newmark PA: The planarian Schmidtea mediterranea as a model for epigenetic germ cell specification: analysis of ESTs from the hermaphroditic strain. Proc Natl Acad Sci USA 2005, 102(51):18491-18496.

24. NCBI UniGene database. http://www.ncbi.nlm.nih.gov/unigene/.

25. Wheeler DL, Church DM, Federhen S, Lash AE, Madden TL, Pontius JU, Schuler GD, Schriml LM, Sequeira E, Tatusova TA, Wagner L: Database resources of the National Center for Biotechnology. Nucleic Acids Res 2003, 31:28-33.

26. Sandmann T, Vogg MC, Owlarn S, Boutros M, Bartscherer K: The headregeneration transcriptome of the planarian Schmidtea mediterranea. Genome Biol 2011, 12(8):R76.

27. Abril JF, Cebrià F, Rodríguez-Esteban G, Horn T, Fraguas S, Calvo B, Bartscherer K, Saló E: Smed454 dataset: unravelling the transcriptome of Schmidtea mediterranea. BMC Genomics 2010, 11:731.

28. Blythe MJ, Kao D, Malla S, Rowsell J, Wilson R, Evans D, Jowett J, Hall A, Lemay $V$, Lam S, Aboobaker AA: A dual platform approach to transcript discovery for the planarian Schmidtea mediterranea to establish RNAseq for stem cell and regeneration biology. PLoS One 2010, 5(12):e15617.

29. Egger B, Steinke D, Tarui H, De Mulder K, Arendt D, Borgonie G, Funayama N, Gschwentner R, Hartenstein V, Hobmayer B, Hooge M,
Hrouda M, Ishida S, Kobayashi C, Kuales G, Nishimura O, Pfister D, Rieger R, Salvenmoser W, Smith J, Technau U, Tyler S, Agata K, Salzburger W, Ladurner P: To Be or Not to Be a Flatworm: The Acoel Controversy. PLoS One 2009, 4:e5502.

30. Cebrià F, Newmark PA: Planarian homologs of netrin and netrin receptor are required for proper regeneration of the central nervous system and the maintenance of nervous system architecture. Development 2005 132:3691-3703.

31. Hausdorf B: Early evolution of the bilateria. Syst Biol 2000, 49:130-142.

32. Ross AG, Bartley PB, Sleigh AC, Olds GR, Li Y, Williams GM, McManus DP: Schistosomiasis. N Engl J Med 2002, 346:1212-1220.

33. Mineta K, Nakazawa M, Cebrià F, Ikeo K, Agata K, Gojobori T: Origin and evolutionary process of the CNS elucidated by comparative genomics analysis of planarian ESTs. Proc Natl Acad Sci USA 2003, 100:7666-7671.

34. Yamamoto $\mathrm{H}$, Agata K: Optic chiasm formation in planarian I: Cooperative netrin- and robo-mediated signals are required for the early stage of optic chiasm formation. Dev Growth Differ 2011, 53(3):300-311.

35. The Gene Ontology Consortium: Gene ontology: tool for the unification of biology. Nat Genet 2000, 25:25-29.

36. Ewing B, Hillier L, Wendl MC, Green P: Base-calling of automated sequencer traces using Phred. I Accuracy Assessment Genome Res 1998, 8:175-185.

37. Huang X, Madan A: CAP3: a DNA sequence assembly program. Genome Res 1999, 9:868-877.

38. Pertea G, Huang X, Liang F, Antonescu V, Sultana R, Karamycheva S, Lee Y, White J, Cheung F, Parvizi B, Tsai J, Quackenbush J: TIGR gene indices clustering tools (TGICL): a software system for fast clustering of large EST datasets. Bioinformatics 2002, 19:651-652.

39. Takechi M, Takeuchi M, Ota KG, Nishimura O, Mochii M, Itomi K, Adachi N, Takahashi M, Fujimoto S, Tarui H, Okabe M, Aizawa S, Kuratani S: Overview of the transcriptome profiles identified in hagfish, shark, and bichir: current issues arising from some nonmodel vertebrate taxa. J Exp Zool B Mol Dev Evol 2011, 316:526-546.

40. Gorodkin J, Cirera S, Hedegaard J, Gilchrist MJ, Panitz F, Jørgensen C, Scheibye-Knudsen K, Arvin T, Lumholdt S, Sawera M, Green T, Nielsen BJ, Havgaard JH, Rosenkilde C, Wang J, Li H, Li R, Liu B, Hu S, Dong W, Li W, Yu J, Wang J, Staefeldt HH, Wernersson R, Madsen LB, Thomsen B, Hornshøj H, Bujie Z, Wang X, Wang X, Bolund L, Brunak S, Yang H, Bendixen C, Fredholm M: Porcine transcriptome analysis based on 97 non-normalized cDNA libraries and assembly of 1,021,891 expressed sequence tags. Genome Biol 2007, 8:R45.

41. Altschul SF, Madden TL, Schaffer AA, Zhang J, Zhang Z, Miller W, Lipman DJ: Gapped BLAST and PSI-BLAST: a new generation of protein database search programs. Nucleic Acids Res 1997, 25:3389-3402.

42. Marchler-Bauer A, Bryant SH: CD-Search: protein domain annotations on the fly. Nucleic Acids Res 2004, 32:W327-W331.

43. Pruitt KD, Tatusova T, Klimke W, Maglott DR: NCBI Reference Sequences: current status, policy and new initiatives. Nucleic Acids Res 2009, 37:D32-D36.

44. Klimke W, Agarwala R, Badretdin A, Chetvernin S, Ciufo S, Fedorov B, Kiryutin B, O'Neill K, Resch W, Resenchuk S, Schafer S, Tolstoy I, Tatusova T: The National Center for Biotechnology Information's Protein Clusters Database. Nucleic Acids Res 2009, 37:D216-D223.

45. Finn RD, Mistry J, Tate J, Coggill P, Heger A, Pollington JE, Gavin OL, Gunasekaran P, Ceric G, Forslund K, Holm L, Sonnhammer EL, Eddy SR, Bateman A: The Pfam protein families database. Nucleic Acids Res 2010, 38:D211-D222.

46. The UniProt Consortium: The Universal Protein Resource (UniProt) in 2010. Nucleic Acids Res 2010, 38:D142-D148.

47. Camon E, Magrane M, Barrell D, Lee V, Dimmer E, Maslen J, Binns D, Harte $\mathrm{N}$, Lopez R, Apweiler R: The gene ontology annotation (goa) database: sharing knowledge in uniprot with gene ontology. Nucleic Acids Res 2004, 32:D262-D266.

48. Götz S, García-Gómez JM, Terol J, Williams TD, Nagaraj SH, Nueda MJ, Robles M, Talón M, Dopazo J, Conesa A: High-throughput functional annotation and data mining with the Blast2GO suite. Nucleic Acids Res 2008, 36:3420-3435.

49. Tatusov RL, Fedorova ND, Jackson JD, Jacobs AR, Kiryutin B, Koonin EV Krylov DM, Mazumder R, Mekhedov SL, Nikolskaya AN, Rao BS, Smirnov S, Sverdlov AV, Vasudevan S, Wolf YI, Yin JJ, Natale DA: The COG database: an updated version includes eukaryotes. BMC Bioinforma 2003, 4:41. 
50. Kent WJ: BLAT—-the BLAST-like alignment tool. Genome Res 2002, 12:656-664.

51. Henikoff S, Henikoff JG: Amino acid substitution matrices from protein blocks. Proc Natl Acad Sci USA 1992, 89:10915-10919.

52. Brouwers JF, Smeenk IM, van Golde LM, Tielens AG: The incorporation, modification and turnover of fatty acids in adult Schistosoma mansoni. Mol Biochem Parasitol 1997, 88:175-185.

53. Chou HH, Holmes MH: DNA sequence quality trimming and vector removal. Bioinformatics 2001, 17:1093-1104.

54. Schistosoma mansoni genome resources. http://www.sanger.ac.uk/resources/ downloads/helminths/schistosoma-mansoni.html.

55. Schmidtea mediterranea genome resources. http://genome.wustl.edu/ genomes/view/schmidtea_mediterranea/.

doi:10.1186/1471-2164-13-289

Cite this article as: Nishimura et al.: Comparative transcriptome analysis between planarian Dugesia japonica and other platyhelminth species. BMC Genomics 2012 13:289.

\section{Submit your next manuscript to BioMed Central and take full advantage of:}

- Convenient online submission

- Thorough peer review

- No space constraints or color figure charges

- Immediate publication on acceptance

- Inclusion in PubMed, CAS, Scopus and Google Scholar

- Research which is freely available for redistribution 